\title{
BMJ Open Comparative efficacy and safety of treatments for localised prostate cancer: an application of network meta-analysis
}

\author{
Tengbin Xiong, ${ }^{1}$ Rebecca M Turner, ${ }^{2}$ Yinghui Wei, ${ }^{3,4}$ David E Neal, ${ }^{1}$ \\ Georgios Lyratzopoulos, ${ }^{5}$ Julian P T Higgins ${ }^{2,6}$
}

To cite: Xiong T, Turner RM, Wei $Y$, et al. Comparative efficacy and safety of treatments for localised prostate cancer: an application of network metaanalysis. BMJ Open 2014;4: e004285. doi:10.1136/ bmjopen-2013-004285

- Prepublication history and additional material is available. To view please visit the journal (http://dx.doi.org/ 10.1136/bmjopen-2013004285).

Received 18 October 2013 Revised 14 April 2014 Accepted 15 April 2014

CrossMark

For numbered affiliations see end of article.

Correspondence to Dr Tengbin Xiong; t.xiong@outlook.com

\section{ABSTRACT}

Context: There is ongoing uncertainty about the optimal management of patients with localised prostate cancer.

Objective: To evaluate the comparative efficacy and safety of different treatments for patients with localised prostate cancer.

Design: Systematic review with Bayesian network metaanalysis to estimate comparative ORs, and a score $(0-100 \%)$ that, for a given outcome, reflects average rank order of superiority of each treatment compared against all others, using the Surface Under the Cumulative RAnking curve (SUCRA) statistic.

Data sources: Electronic searches of MEDLINE without language restriction.

Study selection: Randomised trials comparing the efficacy and safety of different primary treatments (48 papers from 21 randomised trials included 7350 men).

Data extraction: 2 reviewers independently extracted data and assessed risk of bias.

Results: Comparative efficacy and safety evidence was available for prostatectomy, external beam radiotherapy (different types and regimens), observational management and cryotherapy, but not high-intensity focused ultrasound. There was no evidence of superiority for any of the compared treatments in respect of allcause mortality after 5 years. Cryotherapy was associated with less gastrointestinal and genitourinary toxicity than radiotherapy (SUCRA: $99 \%$ and $77 \%$ for gastrointestinal and genitourinary toxicity, respectively).

Conclusions: The limited available evidence suggests that different treatments may be optimal for different efficacy and safety outcomes. These findings highlight the importance of informed patient choice and shared decision-making about treatment modality and acceptable trade-offs between different outcomes. More trial evidence is required to reduce uncertainty. Network meta-analysis may be useful to optimise the power of evidence synthesis studies once data from new randomised controlled studies in this field are published in the future.

\section{BACKGROUND}

Prostate cancer is a worldwide major public health issue. ${ }^{1}$ Nearly $75 \%$ of diagnosed cases,

\section{Strengths and limitations of this study}

- Network meta-analysis enabled us to integrate evidence from direct comparisons (treatments compared head to head within a randomised trial) and indirect comparisons (treatments compared by combining the results of randomised trials with common comparators).

- This network meta-analysis only included randomised controlled trials and the risk of bias in each included study had been comprehensively assessed by using the Cochrane Collaboration's Risk of Bias tool, which strengthens the robustness of evidence synthesis.

- The number of available randomised controlled trials was small which could be a limitation of the study.

however, occur in developed countries, ${ }^{2}$ where it is typically the most common cancer in men. ${ }^{3}{ }^{4}$ In the UK, about 40000 men are diagnosed with prostate cancer and 10000 men die from it every year. ${ }^{3}$ In the USA, there are 240000 new diagnoses of prostate cancer, with 34000 associated deaths every year. ${ }^{5}$ Most patients with prostate cancer are diagnosed at an early stage, ${ }^{6} 7$ and many diagnoses are made in asymptomatic men. ${ }^{8-10}$

The main treatment options for localised prostate cancer include radical prostatectomy, external beam radiotherapy and observational management (ie, regular testing of clinical, biochemical or radiological markers or as prompted by occurrence of symptoms). ${ }^{8}$ As some of these treatments are associated with substantial risk of side effects, it is important to try to resolve the current uncertainty about the optimal treatment options.

Some randomised trials have compared the efficacy and safety of two or three treatments. For example, the SPCG-4 trial in Europe and the PIVOT study in the USA compared radical prostatectomy with observational management. ${ }^{11}{ }^{12}$ The UK Prostate Testing for Cancer and Treatment (ProtecT) 
trial is evaluating treatment effectiveness of active monitoring, radical prostatectomy and external beam radiotherapy for clinically localised prostate cancer in men aged 50-69 years identified through population-based prostate-specific antigen (PSA) testing. ${ }^{13}$ The recruitment phase for the ProtecT trial, which began in 1999, has been completed, but outcomes will not be available until a minimum follow-up period has been accrued.

It is unlikely that any single trial will compare all available treatment options. We therefore performed a network meta-analysis based on a systematic review of completed randomised trials comparing different interventions for patients with localised prostate cancer. The network meta-analysis allowed us to integrate evidence from direct comparisons (treatments compared head to head within a randomised trial) and indirect comparisons (treatments compared by combining the results of randomised trials with common comparators) ${ }^{14-16}$ Our objective was to apply the established methodology used in network meta-analysis to an area of clinical practice where no such previous studies existed. In doing so, our aims were to summarise existing evidence; 'map out' current gaps in comparative evidence to help motivate the design and conduct of future comparative studies and develop an approach 'primed' for subsequent updating and incorporation of future trial evidence.

\section{METHODS}

\section{Eligibility criteria}

We sought completed randomised trials in men with localised prostate cancer that had compared two or more of the following interventions (as primary treatment, with or without the same adjuvant therapy in all arms): prostatectomy, radiotherapy including brachytherapy, cryotherapy, high-intensity focused ultrasound (HIFU) and observational management. Observational management is characterised by testing of clinical, biochemical or radiological markers of disease progression at regular intervals (typically every 6 months) or as prompted by the occurrence of new symptoms, possibly leading to either radical or palliative treatment. We opted to use the term 'observational management' in preference to active surveillance or active monitoring because the latter terms typically aim to keep men in a window of curability so that only those who require it undergo radical treatment.

Eligible trials had to have reported any of the following efficacy and safety outcomes: all-cause mortality, prostate cancer mortality and gastrointestinal (GI) or genitourinary (GU) toxicity. Studies comparing treatment combinations or sequences (eg, per protocol management by surgery with subsequent radiotherapy) were excluded.

\section{Identification of studies}

We adopted the search strategy of a systematic review that supported the development of clinical guidelines on the diagnosis and treatment of prostate cancer by the UK's National Institute for Health and Clinical Excellence (NICE) in 2008. ${ }^{8}$ Studies had been identified by searching MEDLINE (in 2006) and scanning reference list of papers. We retrieved all relevant randomised trials identified in the NICE guidelines and implemented the same search strategies to update the collection of trials. We restricted the search to the period from January 2005 to September 2012. No language limits were placed on the searches (see online supplementary appendix 1 for full search strategies).

\section{Data extraction}

Two reviewers (TX and RMT) independently screened all the titles and abstracts of the studies retrieved by the searches for potentially eligible trials, and then independently assessed the full articles of these trials to confirm whether they met the eligibility criteria. The results were checked and discussed by TX and RMT to agree on a final list of included studies. Using a structured and piloted data collection form, all relevant data in each included paper were extracted by two reviewers independently (TX and RMT/YW). The data extracted were cross-checked and unresolved discrepancies were referred to a third reviewer; where necessary, problems were discussed in a panel meeting (TX, RMT, YW, JPTH and GL) while DEN acted as a clinical expert advisor.

For each included study, we extracted characteristics of participants and interventions, outcomes reported and collected, sample size (randomised and analysed) in each arm, numerical results, losses to follow-up and details of patients excluded from the analyses. ${ }^{17}$ To inform the appropriateness of including studies in the meta-analysis and facilitate assessment of the strength of the evidence we assessed the risk of bias in each included study using the Cochrane Collaboration's Risk of Bias tool. ${ }^{18}$ Two reviewers (TX and either RMT or YW) completed this independently and agreed on final assessments. The tool assesses risk of bias arising from inadequacies in processes of generation of the random allocation sequence, concealment of the allocation sequence and blinding and from incomplete outcome data and selective outcome reporting.

\section{Outcomes}

We analysed all-cause mortality and cancer-related mortality at 5 years, late GI and late GU toxicity at 3 years. The choice of these follow-up times was pragmatic, as they were the ones most frequently reported in the included trials. Once these time points had been chosen, we extracted the outcome data from the time nearest to these targeted measurement times. Late GI and late GU toxicity were defined as scores $\geq 2$ measured by the Radiation Therapy Oncology Group (RTOG) questionnaire scale at 3 years follow-up. ${ }^{19}$ We have not encompassed biochemical or clinical failure as operational definitions of either of those outcomes tend to be specific to different radical treatment modalities. ${ }^{20}$ 


\section{Statistical analyses}

Initially, we compared each pair of treatments using direct evidence alone, for each outcome. Separate meta-analyses were performed for each pair-wise comparison of interventions: a random-effects model was fitted within each comparison, ${ }^{21}$ with a common between-study heterogeneity variance assumed across comparisons to allow for heterogeneity even when only a single study was available. Results are reported as ORs with $95 \%$ CIs, for every comparison evaluated directly in one or more studies.

Next, we fitted a network meta-analysis model for each outcome separately, ${ }^{22}$ combining direct evidence for each comparison (eg, from studies comparing interventions $\mathrm{A}$ with $\mathrm{B}$ ) with indirect evidence (eg, from studies comparing $\mathrm{A}$ with $\mathrm{C}$ and studies comparing $\mathrm{B}$ with $\mathrm{C}$ ), for all pair-wise comparisons simultaneously. The model accounts explicitly for the binary nature of each outcome using a binomial likelihood function; allows for heterogeneity of treatment effects between trials of the same comparison (assuming the same amount of heterogeneity for each comparison, irrespective of how many trials address it) and enforces an underlying relationship between direct and indirect evidence for a particular comparison, assuming these are consistent between the two sources. For each 'loop' of treatment comparisons from three or more independent sources and for each outcome, we computed the difference between estimates from direct and indirect evidence on the log OR scale. ${ }^{23}$ This provides a measure of inconsistency between the different sources. We did not implement more sophisticated methods for testing or adjusting for inconsistency due to the small number of loops in the network.

Results are reported as ORs with $95 \%$ credible intervals for all pair-wise comparisons of interventions. All analyses were performed within a Bayesian framework, using Markov chain Monte Carlo methods in WinBUGS (MRC Biostatistics Unit, Cambridge, UK). ${ }^{24}$ Informative prior distributions were used for the heterogeneity variance, from a published set of distributions for heterogeneity expected in meta-analyses examining particular intervention and outcome types, ${ }^{25}$ since heterogeneity is imprecisely estimated when the number of studies is small. For all-cause mortality, a log-normal $\left(-3.93,1.51^{2}\right)$ distribution was used. For GI and GU toxicity, a log-normal $\left(-2.01,1.64^{2}\right)$ distribution was used. For cancer-related mortality, a log-normal $\left(-2.89,1.91^{2}\right)$ distribution was used. Vague $\mathrm{N}\left(0,10^{4}\right)$ priors were used for all other model parameters. Results were based on 100000 iterations, following a burn-in of 20000 iterations.

For each outcome, we estimated the probability that each intervention is superior to all others, the second best, the third best and so on, from the rank orderings of the treatments at each iteration of the Markov chain. These ranking probabilities were used to calculate a summary numerical value: the Surface Under the Cumulative RAnking curve (SUCRA). ${ }^{26}$ SUCRA values are expressed as percentages; if an intervention is certainly the best, its
SUCRA value would be $100 \%$, and if an intervention is certainly the worst, its SUCRA value would be $0 \%$. If all interventions are equivalent, we would expect all SUCRA values to be near $50 \%$. We also report the median ranks and 95\% credible intervals for each intervention.

\section{RESULTS}

\section{Included studies and interventions}

The NICE systematic review ${ }^{8}$ had identified 20 reports relating to 14 randomised trials. ${ }^{27-46}$ Our updated searches retrieved 1740 studies and identified 39 reports of relevant randomised trials, of which 30 had not been included in the NICE review (figure 1). ${ }^{4-76}$ One of these reports was the sole report of a trial providing data only on acute toxicity, ${ }^{41}$ one paper reported only clinical failure $^{39}$ and one paper reported biochemical failure, biochemical disease-free survival and quality of life ${ }^{57}$; these three studies were then excluded since they did not report the outcomes of interest to us. In addition to the remaining 47 full papers from peer-reviewed journals, we identified and included in the analysis data from a conference abstract, describing a randomised trial comparing external beam radiotherapy versus watchful waiting, ${ }^{77}$ and reporting data on long-term mortality not previously reported in full-text-related publications. ${ }^{78} 79$

Our searches also identified 16 relevant systematic reviews. ${ }^{80-95}$ We scrutinised the reference lists of all these as well as any further systematic reviews identified by the NICE review, and found no further relevant randomised trials.

The 48 identified reports described 21 randomised trials comparing the effectiveness of different treatments for localised prostate cancer. ${ }^{27-38} 40$ 42-56 58-77 Seventeen trials reported all-cause mortality, 16 trials reported cancer-related mortality, 16 trials reported GI toxicity, 15 trials reported GU toxicity. The characteristics of included studies are summarised in online supplementary appendix 2 .

The risk of bias assessments for the included trials is illustrated in figure 2. Most of the evidence was of moderate-to-good quality. About half of the studies did not report adequate information about allocation sequence generation and allocation sequence concealment. Unblinded designs were used in all trials included; we judged this unlikely to cause bias for objectively measured outcomes such as mortality, but generate bias in the reporting and assessment of patientreported toxicity outcomes. The small number of studies precluded the investigation of potential reporting biases across studies (eg,using funnel plots). Our searches were appropriate, but the possibility of publication bias cannot be excluded. It is unclear, however, whether reporting biases would tend to favour any particular treatment (see online supplementary appendix 3 for details of bias assessments for included trials).

We categorised the interventions into the following eight categories: observational management, 


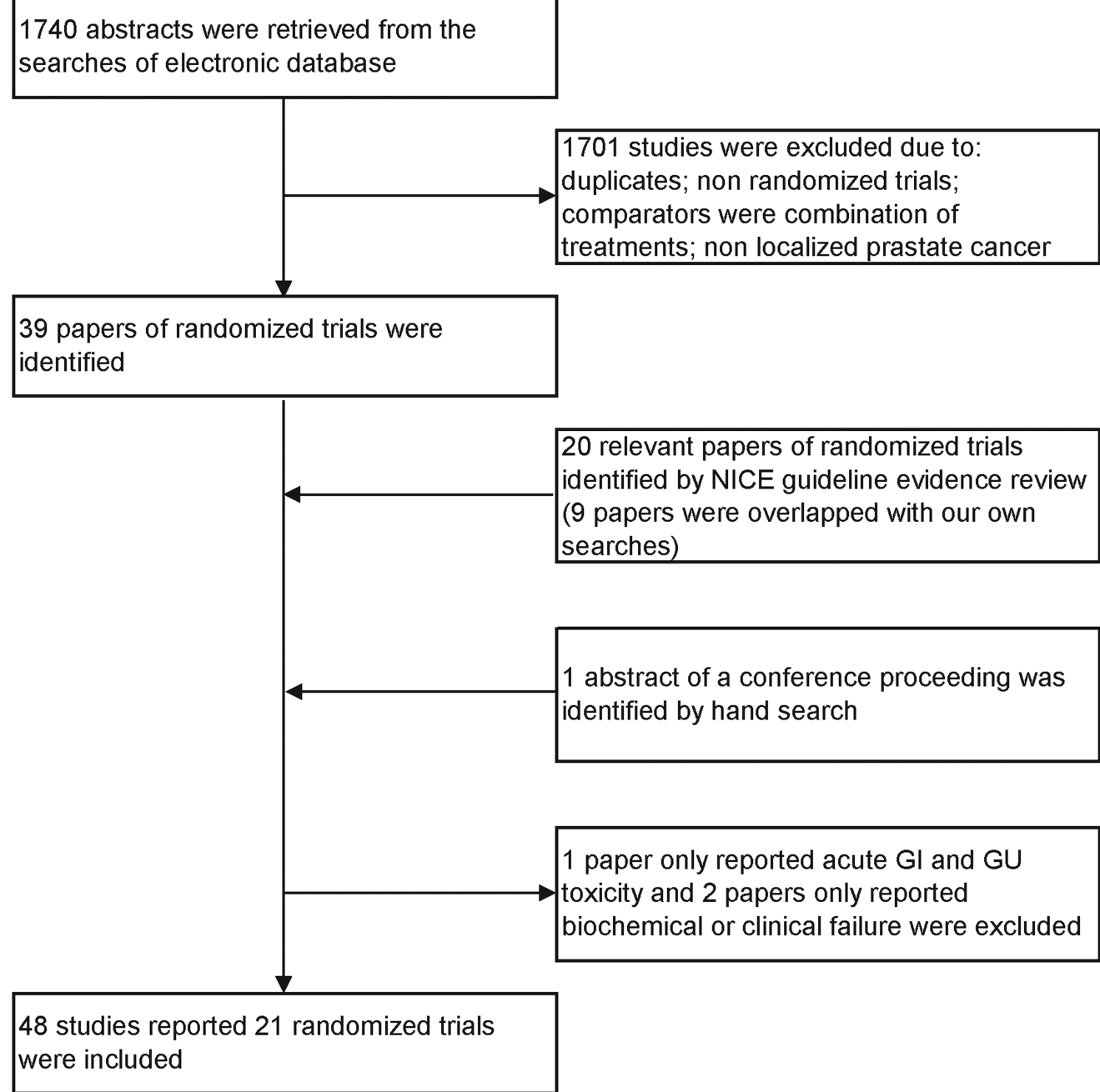

Figure 1 Flowchart of the inclusion process of the studies for network meta-analysis.

prostatectomy, conventional radiotherapy (refers to twodimensional external beam radiation therapy), conventional radiotherapy hypofractionated (refers to less than 20 fractions), conformal low dose (LD) radiotherapy (refers to less than $68 \mathrm{~Gy}$ ), conformal high dose (HD) radiotherapy (refers to more than $74 \mathrm{~Gy}$ ), conformal LD radiotherapy hypofractionated and cryotherapy. Twenty trials had two intervention arms. One trial compared three interventions ${ }^{55}$; since two of the three interventions were very similar and both met our definition of conformal LD radiotherapy hypofractionated, we combined the data from these two arms and regarded the trial as a two-treatment comparison (conformal LD radiotherapy hypofractionated vs conformal HD radiotherapy). None of the reviewed studied assessed brachytherapy and HIFU. Figure 3 illustrates the full network of comparisons. There were two closed loops of comparisons, one connecting prostatectomy, observational management and radiotherapy modalities; and the other connecting different radiotherapy modalities. ${ }^{23}$ No inconsistency was detected in our estimates of the difference between direct and indirect evidence; however, precision was very low. Cryotherapy only had a single link to the network.

\section{All-cause mortality}

All-cause mortality was reported in 17 trials, covering all the eight interventions of interest. There is no evidence of superiority of any treatment for all-cause mortality. For each pair-wise comparison of interventions, the $95 \%$ intervals for ORs were wide and included 1 . The lower-left triangle of results in table 1 presents ORs estimated from direct evidence alone, while the upper-right triangle of results presents ORs estimated from the network meta-analysis. The intervals are slightly narrower when based on indirect as well as direct evidence rather than direct evidence alone. The SUCRA values presented in table 2 summarise the ranking information for all interventions. With respect to all-cause mortality, the highest SUCRA values are $69 \%$ for conformal LD radiotehrapy hypofractionated and $63 \%$ for conformal HD radiotherapy, indicating that these are most likely to be among the best treatments for this outcome. However, there is very 


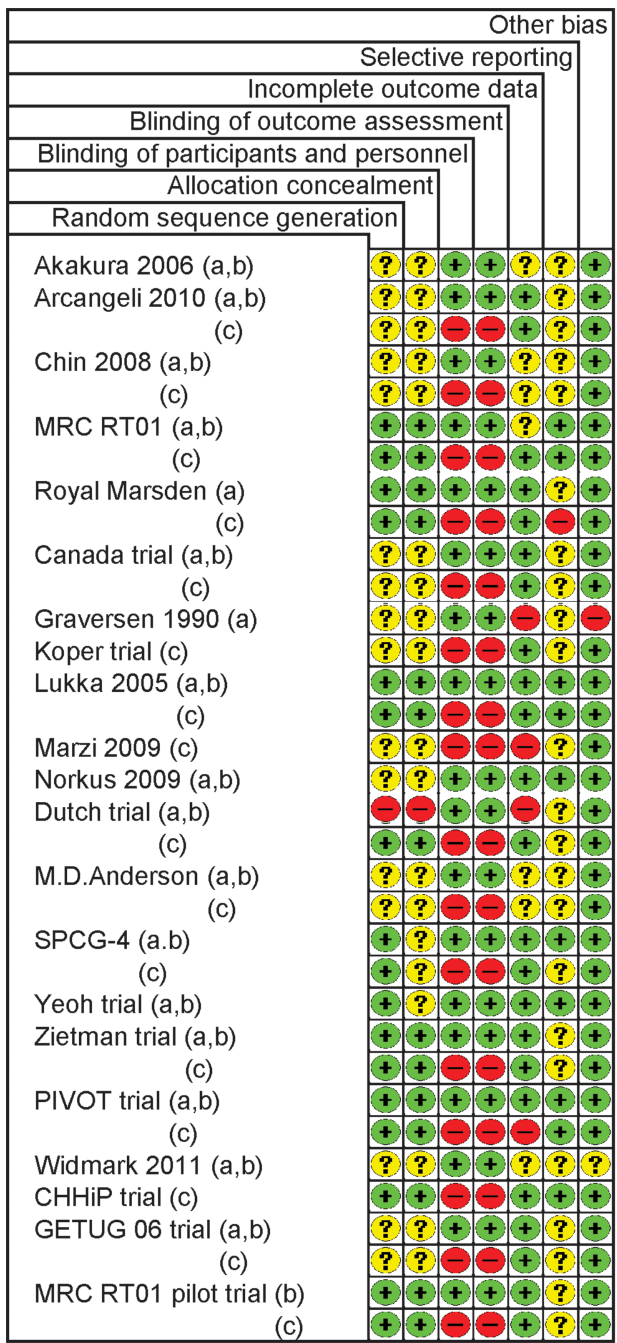

Outcomes measured:

a - all cause mortality.

b - cancer related mortality.

c - gastrointestinal and genitourinary toxicity

Key:

- Low risk of bias

High risk of bias

? Unclear risk of bias

Figure 2 Risk of bias assessments for the included randomised trials.

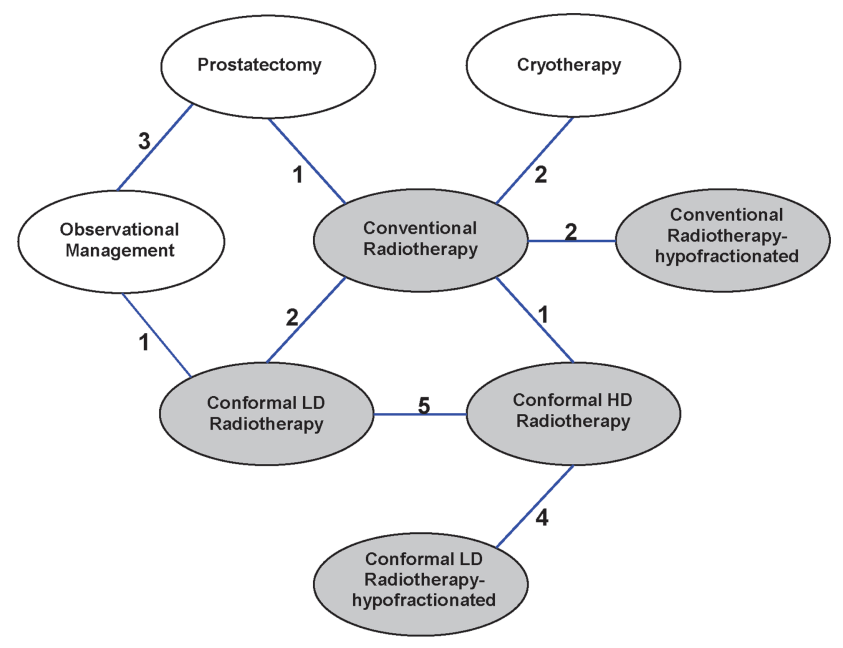

Abbreviations: LD: low dose; HD: high dose.

Grey-shaded ovals indicate external radiotherapy modalities.

Figure 3 Network of comparisons of treatments for localised prostate cancer, showing numbers of trials in which each pair-wise comparison had been made. high uncertainty in the rankings of the interventions, as indicated by wide $95 \%$ credible intervals.

\section{Cancer-related mortality}

Cancer-related mortality was reported in 16 trials, covering eight of the interventions. This was a rare outcome in most treatment groups, as expected for patients with localised prostate cancer with a 5 -year end point. OR estimates had wide $95 \%$ credible intervals, particularly in comparison for which only indirect evidence was available, and there was no evidence of superiority for any of the comparator treatments (table 3). Based on direct comparisons alone, conformal HD radiotherapy was superior to conventional radiotherapy (OR 0.21 (95\% interval 0.03 to 0.97$)$ ) and prostatectomy was superior to observational management (OR 0.60 (95\% interval 0.37 to 0.98$)$ ).

\section{GI and GU toxicity}

Late GI toxicity was reported in 16 trials and late GU toxicity was reported in 15 trials. There was evidence 
Table 1 All-cause mortality: ORs (posterior mean with 95\% intervals) for each pair-wise comparison of interventions, based on direct evidence alone (lower-left triangle) or direct and indirect evidence (upper-right triangle)

\begin{tabular}{|c|c|c|c|c|c|c|c|c|}
\hline Intervention & $\begin{array}{l}\text { Observational } \\
\text { management }\end{array}$ & Prostatectomy & $\begin{array}{l}\text { Conventional } \\
\text { radiotherapy }\end{array}$ & $\begin{array}{l}\text { Conventional } \\
\text { radiotherapy } \\
\text { hypofractionated }\end{array}$ & $\begin{array}{l}\text { Conformal LD } \\
\text { radiotherapy }\end{array}$ & $\begin{array}{l}\text { Conformal HD } \\
\text { radiotherapy }\end{array}$ & $\begin{array}{l}\text { Conformal LD } \\
\text { radiotherapy } \\
\text { hypofractionated }\end{array}$ & Cryotherapy \\
\hline Observational management & & $0.79(0.61,1.02)$ & $0.84(0.48,1.57)$ & $0.72(0.37,1.49)$ & $0.73(0.44,1.26)$ & $0.70(0.40,1.28)$ & $0.53(0.10,2.88)$ & $0.76(0.28,1.98)$ \\
\hline Prostatectomy & ${ }^{3} 0.80(0.61,1.06)$ & & $1.06(0.60,2.02)$ & $0.91(0.46,1.90)$ & $0.92(0.54,1.64)$ & $0.88(0.49,1.66)$ & $0.67(0.12,3.65)$ & $0.96(0.36,2.56)$ \\
\hline Conventional radiotherapy & - & $11.34(0.55,3.24)$ & & $0.85(0.59,1.24)$ & $0.86(0.55,1.35)$ & $0.82(0.51,1.35)$ & $0.62(0.11,3.21)$ & $0.90(0.41,1.89)$ \\
\hline Conventional radiotherapy hypofractionated & - & - & ${ }^{2} 0.85(0.59,1.24)$ & & $1.01(0.56,1.80)$ & $0.97(0.53,1.78)$ & $0.73(0.13,3.86)$ & $1.05(0.44,2.42)$ \\
\hline Conformal LD radiotherapy & ${ }^{1} 0.66(0.35,1.21)$ & - & ${ }^{1} 0.92(0.50,1.72)$ & - & & $0.96(0.72,1.29)$ & $0.72(0.14,3.51)$ & $1.04(0.42,2.49)$ \\
\hline Conformal HD radiotherapy & - & - & ${ }^{1} 0.87(0.39,1.92)$ & - & ${ }^{4} 0.95(0.70,1.31)$ & & $0.74(0.14,3.61)$ & $1.09(0.43,2.64)$ \\
\hline Conformal LD radiotherapy hypofractionated & - & - & - & - & - & ${ }^{2} 0.78(0.13,4.25)$ & & $1.47(0.22,9.40)$ \\
\hline Cryotherapy & - & - & ${ }^{2} 0.90(0.41,2.02)$ & - & - & - & - & \\
\hline
\end{tabular}

Table 2 Ranking of interventions with respect to all-cause and cancer-related mortality, adverse gastrointestinal and genitourinary events: SUCRA values and median ranks (with $95 \%$ intervals)*

\begin{tabular}{|c|c|c|c|c|c|c|c|c|}
\hline \multirow[b]{2}{*}{ Intervention } & \multicolumn{2}{|c|}{ All-cause mortality } & \multicolumn{2}{|c|}{ Cancer-related mortality } & \multicolumn{2}{|c|}{$\begin{array}{l}\text { Adverse gastrointestinal } \\
\text { events }\end{array}$} & \multicolumn{2}{|c|}{ Adverse genitourinary events } \\
\hline & $\begin{array}{l}\text { SUCRA } \\
\text { value (\%) }\end{array}$ & $\begin{array}{l}\text { Median rank } \\
\text { (95\% interval) }\end{array}$ & $\begin{array}{l}\text { SUCRA } \\
\text { value (\%) }\end{array}$ & $\begin{array}{l}\text { Median rank } \\
(95 \% \text { interval) }\end{array}$ & $\begin{array}{l}\text { SUCRA } \\
\text { value (\%) }\end{array}$ & $\begin{array}{l}\text { Median rank } \\
\text { (95\% interval) }\end{array}$ & $\begin{array}{l}\text { SUCRA } \\
\text { value (\%) }\end{array}$ & $\begin{array}{l}\text { Median rank } \\
\text { (95\% interval) }\end{array}$ \\
\hline Observational management & 18 & 7 (2 to 8 ) & 30 & 6 (3 to 8$)$ & - & - & - & - \\
\hline Prostatectomy & 49 & 5 (1 to 7$)$ & 64 & 4 (1 to 7$)$ & - & - & - & - \\
\hline Conventional radiotherapy & 35 & 6 (2 to 8 ) & 16 & 7 (4 to 8$)$ & 43 & 4 (2 to 6$)$ & 51 & 3 (1 to 6$)$ \\
\hline $\begin{array}{l}\text { Conventional radiotherapy } \\
\text { hypofractionated }\end{array}$ & 58 & 4 (1 to 8 ) & 44 & 5 (1 to 8 ) & 42 & 4 (1 to 6$)$ & 50 & 3 (1 to 6 ) \\
\hline Conformal LD radiotherapy & 57 & 4 (1 to 7$)$ & 61 & 4 (2 to 7$)$ & 67 & 2 (2 to 4$)$ & 66 & $3(1$ to 5$)$ \\
\hline Conformal HD radiotherapy & 63 & 3 (1 to 7$)$ & 75 & 2 (1 to 6$)$ & 19 & 5 (3 to 6$)$ & 30 & 5 (2 to 6$)$ \\
\hline $\begin{array}{l}\text { Conformal LD radiotherapy } \\
\text { hypofractionated }\end{array}$ & 69 & 1 (1 to 8$)$ & 85 & 1 (1 to 8$)$ & 30 & 5 (2 to 6$)$ & 26 & $5(1$ to 6$)$ \\
\hline Cryotherapy & 50 & $4(1$ to 8$)$ & 24 & 7 (2 to 8 ) & 99 & 1 (1 to 2$)$ & 77 & 1 (1 to 6$)$ \\
\hline
\end{tabular}

*The SUCRA value is a numerical summary of the estimated probabilities that each treatment is the best, second best, third best (and so on) for that particular outcome. Higher values indicate

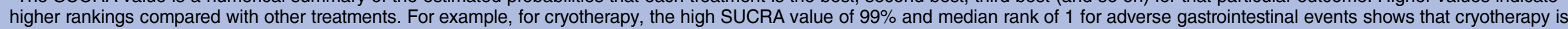
expected to be superior with respect to this outcome.

HD, high dose; LD, low dose; SUCRA, Surface Under the Cumulative RAnking curve. 
that cryotherapy resulted in fewer adverse GI events than radiotherapy treatments (estimated ORs comparing cryotherapy against the five radiotherapy options ranged from 0.12 to 0.24 , while all but one of the respective $95 \%$ credible intervals excluded 1 ). The SUCRA value of 99\% for cryotherapy and the median rank of $1(95 \%$ interval 1,2 ) suggest that cryotherapy is almost certainly superior among the six treatments included in the network meta-analysis in relation to adverse GI events (tables 2 and 4). There was also evidence that GI toxicity was more likely with conformal HD radiotherapy than with conformal LD radiotherapy. Interpretation of such findings for toxicity should be more cautious than for the other outcomes, due to a concern that lack of blinding could have led to a risk of detection bias. For GU toxicity, there was no evidence favouring one intervention over another (table 5), although cryotherapy tended to receive better rankings than the five radiotherapy treatments (table 2), and the OR estimates favour cryotherapy, but the $95 \%$ intervals all included 1.

\section{DISCUSSION}

Using network meta-analysis, we were able to combine simultaneously all relevant evidence on treating patients with localised prostate cancer, even in the absence of direct comparative evidence for some treatment pairs, encompassing four efficacy and safety outcomes. Based on data from 21 trials including 7350 patients randomly assigned among eight different intervention regimes for localised prostate cancer, we found substantial uncertainty about the relative efficacy and safety of different interventions in respect of the studied outcomes.

Assumptions of consistency between direct and indirect evidence were tested to justify the joint synthesis of all studies; however, these tests had little power due to the relatively small number of trials available in most direct comparisons. Instead we must rely on judgements about the similarity of studies included in the analysis in aspects such as patient groups, outcome measures and study methodology. Although we defined the population of interest as patients with localised prostate cancer, there was heterogeneity between individual study populations in terms of the severity of disease. Some of the trials were conducted several decades ago, when surgery and radiology techniques may have been different, and we observed that stage migration has occurred in men diagnosed with prostate cancer due to emerging biomarker and image technologies. Furthermore, some of the trials used adjuvant therapy, although this was applied in all the arms within the trial.

Two further limitations warrant mention. Literature searches were completed in September of 2012. However, the results of one of the most important randomised trials-ProtecT study ${ }^{13}$ - has not been published so far, and to our knowledge no other new relevant randomised controlled trials (RCTs) have been

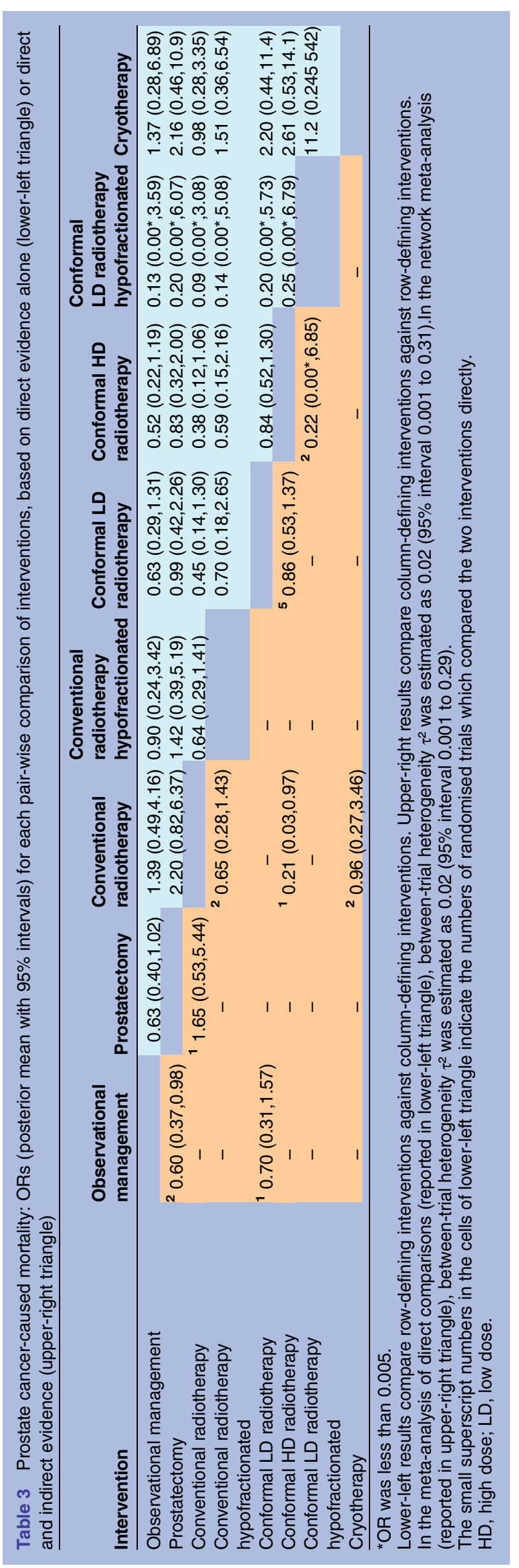


Table 4 Adverse gastrointestinal events: ORs (posterior mean with 95\% intervals) for each pair-wise comparison of interventions, based on direct evidence alone (lower-left triangle) or direc and indirect evidence (upper-right triangle)

\begin{tabular}{|c|c|c|c|c|c|c|c|c|}
\hline Intervention & $\begin{array}{l}\text { Observational } \\
\text { management }\end{array}$ & Prostatectomy & $\begin{array}{l}\text { Conventional } \\
\text { radiotherapy }\end{array}$ & $\begin{array}{l}\text { Conventional } \\
\text { radiotherapy } \\
\text { hypofractionated }\end{array}$ & $\begin{array}{l}\text { Conformal LD } \\
\text { radiotherapy }\end{array}$ & $\begin{array}{l}\text { Conformal HD } \\
\text { radiotherapy }\end{array}$ & $\begin{array}{l}\text { Conformal LD } \\
\text { radiotherapy } \\
\text { hypofractionated }\end{array}$ & Cryotherapy \\
\hline Observational management & & - & - & - & - & - & - & - \\
\hline Prostatectomy & ${ }^{2} 0.84(0.33,1.88)$ & & - & - & - & - & - & - \\
\hline Conventional radiotherapy & - & - & & $1.01(0.19,5.29)$ & $0.72(0.29,1.59)$ & $1.42(0.57,3.39)$ & $1.26(0.35,4.30)$ & $0.17(0.04,0.51)$ \\
\hline Conventional radiotherapy hypofractionated & - & - & $11.00(0.22,4.56)$ & & $0.70(0.11,4.37)$ & $1.40(0.21,9.02)$ & $1.24(0.15,9.76)$ & $0.17(0.02,1.19)$ \\
\hline Conformal LD radiotherapy & - & - & ${ }^{2} 0.46(0.17,1.16)$ & - & & $1.98(1.18,3.59)$ & $1.77(0.63,5.11)$ & $0.24(0.05,0.96)$ \\
\hline Conformal HD radiotherapy & - & - & ${ }^{1} 2.66(0.85,8.62)$ & - & $51.73(1.07,2.97)$ & & $0.89(0.36,2.15)$ & $0.12(0.02,0.48)$ \\
\hline Conformal LD radiotherapy hypofractionated & - & - & - & - & - & ${ }^{3} 0.89(0.39,1.96)$ & & $0.14(0.02,0.70)$ \\
\hline Cryotherapy & - & - & ${ }^{2} 0.18(0.05,0.50)$ & - & - & - & - & \\
\hline
\end{tabular}

Cryotherapy

Lower-left results compare row-defining interventions against column-defining interventions. Upper-right results compare column-defining interventions against row-defining interventions.

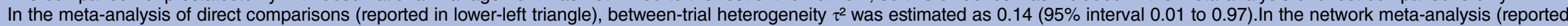

in upper-right triangle), between-trial heterogeneity $\tau^{2}$ was estimated as 0.24 (95\% interval 0.02 to 1.23 ).

The small superscript numbers in the cells of lower-left triangle indicate the numbers of randomised trials which compared the two interventions directly.

HD, high dose; LD, low dose.

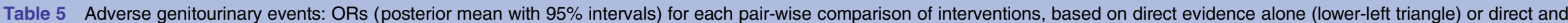
indirect evidence (upper-right triangle)

\begin{tabular}{|c|c|c|c|c|c|c|c|c|}
\hline Intervention & $\begin{array}{l}\text { Observational } \\
\text { management }\end{array}$ & Prostatectomy & $\begin{array}{l}\text { Conventional } \\
\text { radiotherapy }\end{array}$ & $\begin{array}{l}\text { Conventional } \\
\text { radiotherapy } \\
\text { hypofractionated }\end{array}$ & $\begin{array}{l}\text { Conformal LD } \\
\text { radiotherapy }\end{array}$ & $\begin{array}{l}\text { Conformal HD } \\
\text { radiotherapy }\end{array}$ & $\begin{array}{l}\text { Conformal LD } \\
\text { radiotherapy } \\
\text { hypofractionated }\end{array}$ & Cryotherapy \\
\hline Observational management & & - & - & - & - & - & - & - \\
\hline Prostatectomy & ${ }^{2} 2.27(1.34,3.90)$ & & - & - & - & - & - & - \\
\hline Conventional radiotherapy & - & - & & $1.00(0.34,2.90)$ & $0.91(0.54,1.51)$ & $1.19(0.69,2.11)$ & $1.41(0.49,4.07)$ & $0.66(0.22,2.00)$ \\
\hline Conventional radiotherapy hypofractionated & - & - & ${ }^{1} 1.01(0.34,3.00)$ & & $0.90(0.27,2.97)$ & $1.19(0.36,4.04)$ & $1.41(0.31,6.44)$ & $0.66(0.14,3.04)$ \\
\hline Conformal LD radiotherapy & - & - & ${ }^{2} 0.80(0.43,1.51)$ & - & & $1.32(0.97,1.86)$ & $1.56(0.61,4.09)$ & $0.73(0.21,2.52)$ \\
\hline Conformal HD radiotherapy & - & - & ${ }^{1} 1.53(0.62,3.82)$ & - & $51.28(0.93,1.86)$ & & $1.18(0.48,2.92)$ & $0.55(0.16,1.91)$ \\
\hline Conformal LD radiotherapy hypofractionated & - & - & - & - & - & ${ }^{2} 1.17(0.48,2.91)$ & & $0.47(0.10,2.15)$ \\
\hline Cryotherapy & _- & _- & ${ }^{2} 0.68(0.22,2.03)$ & _- & _- & - & _- & \\
\hline
\end{tabular}

Lower-left results compare row-defining interventions against column-defining interventions. Upper-right results compare column-defining interventions against row-defining interventions.

The comparison of prostatectomy with observational management was not linked to the rest of the network, so this evidence was included in the meta-analysis of direct comparisons only

In the meta-analysis of direct comparisons (reported in lower-left triangle), between-trial heterogeneity $\tau^{2}$ was estimated as 0.04 (95\% interval 0.003 to 0.29 ). In the network meta-analysis

(reported in upper-right triangle), between-trial heterogeneity $\tau^{2}$ was estimated as 0.04 ( $95 \%$ interval 0.002 to 0.26 ).

The small superscript numbers in the cells of lower-left triangle indicate the numbers of randomised trials which compared the two interventions directly.

HD, high dose; LD, low dose. 
reported after this systematic review. Our choices of measurements may have favoured some treatments over others: for example, the RTOG scale had been used to define the late GI and late GU toxicity in the included studies, but it does not measure incontinence which could be the most common adverse event postprostatectomy. ${ }^{96}$

Methodologically, we used informative prior distributions based on external evidence for heterogeneity variances to increase precision in their estimation and improve estimation of treatment differences. Data-based informative priors have previously been considered by Lu and Ades, ${ }^{97}$ who used them for the between-study correlation structure. To our knowledge, our paper is the first application of network meta-analysis incorporating data-based informative priors for between-study heterogeneity.

Our findings have implications for research funding prioritisation and study design, and for clinical practice. The study identified particular 'weak links' in the network of comparative treatment options, which might be prioritised for future investment in RCTs. This is particularly the case for studies comparing HIFU (which currently is bereft of any comparative evidence) or brachytherapy against other treatment options, and also for trials examining the comparative efficacy and safety of prostatecotmy versus conformal radiotherapy modalities. For clinicians, and for men diagnosed with prostate cancer, our findings highlight that the optimal treatment options may be different in respect of different outcomes: patients need to be given appropriate information about the uncertainty surrounding treatment choice currently, and be allowed to opt for 'trade-offs' between efficacy and safety outcomes as they judge appropriately. ${ }^{98}$ Observational studies have consistently shown that radical prostatectomy has better cause-specific mortality outcomes compared with radiotherapy. ${ }^{99-103}$

In conclusion, clinically important information from high-quality randomised trials is still needed to inform decision-making regarding primary treatment options for men with localised prostate cancer. The findings of this study highlight the importance of informed patient choice and shared decision-making about treatment modality and acceptable trade-offs between multiple outcomes. The upcoming results of the ProtecT study, ${ }^{13}$ which is evaluating effectiveness of multiple therapies in men with PSA-detected localised prostate cancer, together with other treatment studies in progress, will hopefully contribute to the evidence base. It is, however, unlikely that evidential uncertainty about all relevant and important outcomes will be resolved by these trials, and an updated network meta-analysis incorporating new evidence may be useful to synthesise the new with the existing evidence. We demonstrate a high degree of uncertainty about treatment superiority in the management of localised prostate cancer. Clinicians and patients need to grapple with this uncertainty in the context of shared decision-making.
Author affiliations

${ }^{1}$ Department of Oncology, University of Cambridge, Addenbrooke's Hospital, Cambridge, UK

${ }^{2}$ MRC Biostatistics Unit, Institute of Public Health, Forvie Site, Cambridge, UK ${ }^{3}$ MRC Clinical Trials Unit, London Hub for Trials Methodology Research, London, UK

${ }^{4}$ School of Computing and Mathematics, Plymouth University, Plymouth, UK ${ }^{5}$ Department of Public Health and Primary Care, Cambridge Centre for Health Services Research, University of Cambridge, Cambridge, UK

${ }^{6}$ Centre for Reviews and Dissemination, University of York, York, UK

Contributors TX, RMT, GL and JPTH conceived and designed the study. TX performed the literature searches. TX, RMT, YW, GL and JPTH performed the literature review and data extraction. TX, RMT, YW, GL and JPTH analysed the data. TX wrote the first draft of the manuscript. TX, RMT, YW, DEN, GL and JPTH contributed to the writing of the manuscript.

Funding TX was funded by the National Institute for Health Research Health Technology Assessment (NIHR HTA) programme (HTA 96/20/99). RMT was supported by Medical Research council grant U105285807. GL was supported by a Post-Doctoral Fellowship Award of the National Institute for Health Research (PDF-2011-04-047).

Competing interests None.

Provenance and peer review Not commissioned; externally peer reviewed.

Data sharing statement No additional data are available.

Open Access This is an Open Access article distributed in accordance with the Creative Commons Attribution Non Commercial (CC BY-NC 3.0) license, which permits others to distribute, remix, adapt, build upon this work noncommercially, and license their derivative works on different terms, provided the original work is properly cited and the use is non-commercial. See: http:// creativecommons.org/licenses/by-nc/3.0/

\section{REFERENCES}

1. Jemal A, Bray F, Center MM, et al. Global cancer statistics. $C A$ Cancer J Clin 2011;61:69-90.

2. Ferlay J, Shin HR, Bray F, et al. GLOBOCAN 2008 v1.2, Cancer incidence and mortality worldwide: IARC CancerBase No.10. Lyon, France: International Agency for Research on Cancer, 2010. http:// globocan.iarc.fr (accessed 8 Aug 2011).

3. Cancer Research UK. Prostate cancer-UK incidence statistics. http://info.cancerresearchuk.org/cancerstats/types/prostate/ incidence/ (accessed 8 Aug, 2011).

4. Howlader N, Noone AM, Krapcho M, et al. SEER cancer statistics review, 1975-2008. Bethesda, MD: National Cancer Institute, 2011. http://seer.cancer.gov/csr/1975_2008/, based on November 2010 SEER data submission, posted to the SEER web site.

5. National Cancer Institute. Prostate cancer. http://www.cancer.gov/ cancertopics/types/prostate (accessed 8 Aug 2011).

6. National Cancer Institute. Cancer advances in focus-prostate cancer. http://www.cancer.gov/cancertopics/factsheet/canceradvances-in-focus/prostate (accessed 8 Aug 2011).

7. Lyratzopoulos G, Barbiere JM, Greenberg DC, et al. Population based time trends and socioeconomic variation in use of radiotherapy and radical surgery for prostate cancer in a UK region: continuous survey. BMJ 2010;340:c1928.

8. National Collaborating Centre for Cancer. NICE clinical guideline 58. Prostate cancer: diagnosis and treatment. Evidence review. London: National Institute for Health and Clinical Excellence, 2008.

9. Heidenreich A, Bastian PJ, Bellmunt J, et al. Guidelines on prostate cancer. European Accosication of Urology, 2012.

10. Thompson I, Thrasher JB, Aus G, et al. Guideline for the management of clinically localized prostate cancer: 2007 update. American Urological Association, 2011.

11. Andersson SO, Andren O, Lyth J, et al. Managing localized prostate cancer by radical prostatectomy or watchful waiting: cost analysis of a randomized trial (SPCG-4). Scand J Urol Nephrol 2011;45:177-83

12. Wilt TJ, Brawer MK, Barry MJ, et al. The Prostate cancer Intervention Versus Observation Trial:VA/NCI/AHRQ Cooperative Studies Program \#407 (PIVOT): design and baseline results of a randomized controlled trial comparing radical prostatectomy to watchful waiting for men with clinically localized prostate cancer Contemp Clin Trials 2009;30:81-7. 
13. Donovan J, Mills N, Smith M, et al. Quality improvement report: improving design and conduct of randomised trials by embedding them in qualitative research: ProtecT (prostate testing for cancer and treatment) study. Commentary: presenting unbiased information to patients can be difficult. BMJ 2002;325:766-70.

14. Caldwell DM, Ades AE, Higgins JP. Simultaneous comparison of multiple treatments: combining direct and indirect evidence. $B M J$ 2005;331:897-900.

15. Lu G, Ades AE. Combination of direct and indirect evidence in mixed treatment comparisons. Stat Med 2004;23:3105-24.

16. Salanti G, Higgins JP, Ades AE, et al. Evaluation of networks of randomized trials. Stat Methods Med Res 2008;17:279-301.

17. Higgins JPT, Green S. Cochrane handbook for systematic reviews of interventions version 5.1.0 (updated March 2011). The Cochrane Collaboration, 2011. http://www.cochrane-handbook.org

18. Higgins JP, Altman DG, Gotzsche PC, et al. The Cochrane collaboration's tool for assessing risk of bias in randomised trials. BMJ 2011;343:d5928.

19. Pilepich MV, Krall JM, Sause WT, et al. Correlation of radiotherapeutic parameters and treatment related morbidity in carcinoma of the prostate-analysis of RTOG study 75-06. Int $J$ Radiat Oncol Biol Phys 1987;13:351-7.

20. Nielsen ME, Makarov DV, Humphreys E, et al. Is it possible to compare PSA recurrence-free survival after surgery and radiotherapy using revised ASTRO criterion-"nadir + 2"? Urology 2008;72:389-93; discussion 394-385.

21. Smith TC, Spiegelhalter DJ, Thomas A. Bayesian approaches to random-effects meta-analysis: a comparative study. Stat $\mathrm{Med}$ 1995;14:2685-99.

22. Dias S, Welton NJ, Sutton AJ, et al. NICE DSU technical support document 2: a generalised linear modelling framework for pairwise and network meta-analysis of randomised controlled trials. 2011. http://www.nicedsu.org.uk (accessed Apr 2012).

23. Lu G, Ades AE. Assessing evidence inconsistency in mixed treatment comparisons. J Am Stat Assoc 2006;101:447-59.

24. Lunn DJ, Thomas A, Best N, et al. WinBUGS-a Bayesian modelling framework: concepts, structure, and extensibility. Stat Comput 2000;10:325-37.

25. Turner RM, Davey J, Clarke MJ, et al. Predicting the extent of heterogeneity in meta-analysis, using empirical data from the Cochrane database of systematic reviews. Int J Epidemiol 2012;41:818-27.

26. Salanti G, Ades AE, loannidis JP. Graphical methods and numerical summaries for presenting results from multiple-treatment meta-analysis: an overview and tutorial. J Clin Epidemiol 2011;64:163-71.

27. Akakura $\mathrm{K}$, Suzuki $\mathrm{H}$, Ichikawa $\mathrm{T}$, et al. A randomized trial comparing radical prostatectomy plus endocrine therapy versus external beam radiotherapy plus endocrine therapy for locally advanced prostate cancer: results at median follow-up of 102 months. Jpn J Clin Oncol 2006;36:789-93.

28. Bill-Axelson A, Holmberg L, Ruutu M, et al. Radical prostatectomy versus watchful waiting in early prostate cancer. $N$ Engl $J$ Med 2005;352:1977-84.

29. Chin JL, Ng CK, Touma NJ, et al. Randomized trial comparing cryoablation and external beam radiotherapy for T2C-T3B prostate cancer. Prostate Cancer Prostatic Dis 2008;11:40-5.

30. Dearnaley DP, Hall E, Lawrence D, et al. Phase III pilot study of dose escalation using conformal radiotherapy in prostate cancer: PSA control and side effects. Br J Cancer 2005;92:488-98.

31. Dearnaley DP, Khoo VS, Norman AR, et al. Comparison of radiation side-effects of conformal and conventional radiotherapy in prostate cancer: a randomised trial. Lancet 1999;353:267-72

32. Dearnaley DP, Sydes MR, Graham JD, et al. Escalated-dose versus standard-dose conformal radiotherapy in prostate cancer: first results from the MRC RT01 randomised controlled trial. Lancet Oncol 2007;8:475-87.

33. Dearnaley DP, Sydes MR, Langley RE, et al. The early toxicity of escalated versus standard dose conformal radiotherapy with neo-adjuvant androgen suppression for patients with localised prostate cancer: results from the MRC RT01 tria (ISRCTN47772397). Radiother Oncol 2007;83:31-41.

34. Donnelly B, Saliken J, Brasher P, et al. Randomized trial of external beam radiotherapy versus cryoablation in patients with localized prostate cancer. The American Urological Association Annual Meeting. Abstract 1141. 2007.

35. Graversen PH, Nielsen KT, Gasser TC, et al. Radical prostatectomy versus expectant primary treatment in stages I and II prostatic cancer. A fifteen-year follow-up. Urology 1990;36:493-8.

36. Koper PC, Jansen P, van Putten W, et al. Gastro-intestinal and genito-urinary morbidity after 3D conformal radiotherapy of prostate cancer: observations of a randomized trial. Radiother Oncol 2004;73:1-9.

37. Koper PC, Stroom JC, van Putten WL, et al. Acute morbidity reduction using 3DCRT for prostate carcinoma: a randomized study. Int J Radiat Oncol Biol Phys 1999;43:727-34.

38. Lukka $\mathrm{H}$, Hayter $\mathrm{C}$, Julian JA, et al. Randomized trial comparing two fractionation schedules for patients with localized prostate cancer. J Clin Oncol 2005;23:6132-8.

39. Paulson DF, Lin GH, Hinshaw W, et al. Radical surgery versus radiotherapy for adenocarcinoma of the prostate. $J$ Urol 1982;128:502-4.

40. Peeters ST, Heemsbergen WD, Koper PC, et al. Dose-response in radiotherapy for localized prostate cancer: results of the Dutch multicenter randomized phase III trial comparing 68 Gy of radiotherapy with 78 Gy. J Clin Oncol 2006;24:1990-6.

41. Pollack A, Hanlon AL, Horwitz EM, et al. Dosimetry and preliminary acute toxicity in the first 100 men treated for prostate cancer on a randomized hypofractionation dose escalation trial. Int J Radiat Oncol Biol Phys 2006;64:518-26.

42. Pollack A, Zagars GK, Starkschall G, et al. Prostate cancer radiation dose response: results of the $M$. D. Anderson phase III randomized trial. Int J Radiat Oncol Biol Phys 2002:53:1097-105.

43. Steineck G, Helgesen F, Adolfsson J, et al. Quality of life after radical prostatectomy or watchful waiting. $N$ Engl J Med 2002;347:790-6.

44. Storey MR, Pollack A, Zagars G, et al. Complications from radiotherapy dose escalation in prostate cancer: preliminary results of a randomized trial. Int J Radiat Oncol Biol Phys 2000;48:635-42.

45. Tait DM, Nahum AE, Meyer LC, et al. Acute toxicity in pelvic radiotherapy; a randomised trial of conformal versus conventional treatment. Radiother Oncol 1997;42:121-36.

46. Yeoh EE, Fraser RJ, McGowan RE, et al. Evidence for efficacy without increased toxicity of hypofractionated radiotherapy for prostate carcinoma: early results of a phase III randomized trial. Int J Radiat Oncol Biol Phys 2003;55:943-55.

47. Al-Mamgani A, van Putten WL, Heemsbergen WD, et al. Update of Dutch multicenter dose-escalation trial of radiotherapy for localized prostate cancer. Int J Radiat Oncol Biol Phys 2008;72:980-8.

48. Al-Mamgani A, van Putten WL, van der Wielen GJ, et al. Dose escalation and quality of life in patients with localized prostate cancer treated with radiotherapy: long-term results of the Dutch randomized dose-escalation trial (CKTO 96-10 trial). Int J Radiat Oncol Biol Phys 2011;79:1004-12.

49. Arcangeli G, Fowler J, Gomellini S, et al. Acute and late toxicity in a randomized trial of conventional versus hypofractionated three-dimensional conformal radiotherapy for prostate cancer. Int $J$ Radiat Oncol Biol Phys 2011;79:1013-21.

50. Arcangeli G, Saracino B, Gomellini S, et al. A prospective phase III randomized trial of hypofractionation versus conventional fractionation in patients with high-risk prostate cancer. Int $J$ Radiat Oncol Biol Phys 2010;78:11-18.

51. Beckendorf V, Guerif S, Le Prise E, et al. 70 Gy versus 80 Gy in localized prostate cancer: 5-year results of GETUG 06 randomized trial. Int J Radiat Oncol Biol Phys 2011;80:1056-63.

52. Beckendorf V, Guerif S, Le Prise E, et al. The GETUG 70 Gy vs. 80 Gy randomized trial for localized prostate cancer: feasibility and acute toxicity. Int J Radiat Oncol Biol Phys 2004:60:1056-65.

53. Bill-Axelson A, Holmberg L, Filen F, et al. Radical prostatectomy versus watchful waiting in localized prostate cancer: the Scandinavian prostate cancer group-4 randomized trial. J Nat Cancer Inst 2008;100:1144-54.

54. Bill-Axelson A, Holmberg L, Ruutu M, et al. Radical prostatectomy versus watchful waiting in early prostate cancer. $N$ Engl $J$ Med 2011;364:1708-17.

55. Dearnaley D, Syndikus I, Sumo G, et al. Conventional versus hypofractionated high-dose intensity-modulated radiotherapy for prostate cancer: preliminary safety results from the $\mathrm{CHHiP}$ randomised controlled trial. Lancet Oncol 2012;13:43-54.

56. Donnelly BJ, Saliken JC, Brasher PM, et al. A randomized trial of external beam radiotherapy versus cryoablation in patients with localized prostate cancer. Cancer 2010;116:323-30.

57. Giberti C, Chiono L, Gallo F, et al. Radical retropubic prostatectomy versus brachytherapy for low-risk prostatic cancer: a prospective study. World J Urol 2009;27:607-12.

58. Heemsbergen WD, Hoogeman MS, Witte MG, et al. Increased risk of biochemical and clinical failure for prostate patients with a large rectum at radiotherapy planning: results from the Dutch trial of 68 GY versus 78 Gy. Int J Radiat Oncol Biol Phys 2007;67:1418-24.

59. Johansson E, Bill-Axelson A, Holmberg L, et al. Time, symptom burden, androgen deprivation, and self-assessed quality of life after 
radical prostatectomy or watchful waiting: the Randomized Scandinavian Prostate Cancer Group Study Number 4 (SPCG-4) clinical trial. Eur Urol 2009;55:422-30.

60. Johansson E, Steineck G, Holmberg L, et al. Long-term quality-of-life outcomes after radical prostatectomy or watchful waiting: the Scandinavian Prostate Cancer Group-4 randomised trial. Lancet Oncol 2011;12:891-9.

61. Kuban DA, Levy LB, Cheung MR, et al. Long-term failure patterns and survival in a randomized dose-escalation trial for prostate cancer. Who dies of disease? Int J Radiat Oncol Biol Phys 2011;79:1310-17.

62. Kuban DA, Tucker SL, Dong L, et al. Long-term results of the M. D. Anderson randomized dose-escalation trial for prostate cancer. Int J Radiat Oncol Biol Phys 2008;70:67-74.

63. Marzi S, Saracino B, Petrongari MG, et al. Modeling of alpha/beta for late rectal toxicity from a randomized phase II study: conventional versus hypofractionated scheme for localized prostate cancer. J Exp Clin Cancer Res 2009;28:117.

64. Norkus D, Miller A, Kurtinaitis J, et al. A randomized trial comparing hypofractionated and conventionally fractionated three-dimensional external-beam radiotherapy for localized prostate adenocarcinoma: a report on acute toxicity. Strahlenther Onkol 2009;185:715-21.

65. Norkus D, Miller A, Plieskiene A, et al. A randomized trial comparing hypofractionated and conventionally fractionated three-dimensional conformal external-beam radiotherapy for localized prostate adenocarcinoma: a report on the first-year biochemical response. Medicina (Kaunas) 2009;45:469-75.

66. Peeters ST, Heemsbergen WD, van Putten WL, et al. Acute and late complications after radiotherapy for prostate cancer: results of a multicenter randomized trial comparing 68 Gy to 78 Gy. Int $J$ Radiat Oncol Biol Phys 2005;61:1019-34.

67. Peeters ST, Lebesque JV, Heemsbergen WD, et al. Localized volume effects for late rectal and anal toxicity after radiotherapy for prostate cancer. Int J Radiat Oncol Biol Phys 2006;64:1151-61.

68. Robinson JW, Donnelly BJ, Siever JE, et al. A randomized trial of external beam radiotherapy versus cryoablation in patients with localized prostate cancer: quality of life outcomes. Cancer 2009;115:4695-704

69. Syndikus I, Morgan RC, Sydes MR, et al. Late gastrointestinal toxicity after dose-escalated conformal radiotherapy for early prostate cancer: results from the UK Medical Research Counci RT01 trial (ISRCTN47772397). Int J Radiat Oncol Biol Phys 2010;77:773-83.

70. van der Wielen GJ, Hoogeman MS, Dohle GR, et al. Dose-volume parameters of the corpora cavernosa do not correlate with erectile dysfunction after external beam radiotherapy for prostate cancer: results from a dose-escalation trial. Int J Radiat Oncol Biol Phys 2008;71:795-800.

71. Wilt TJ, Brawer MK, Jones KM, et al. Radical prostatectomy versus observation for localized prostate cancer. N Engl J Med 2012;367:203-13.

72. Yeoh EE, Botten RJ, Butters J, et al. Hypofractionated versus conventionally fractionated radiotherapy for prostate carcinoma: final results of phase III randomized trial. Int J Radiat Oncol Biol Phys 2011;81:1271-8.

73. Yeoh EE, Holloway RH, Fraser RJ, et al. Hypofractionated versus conventionally fractionated radiation therapy for prostate carcinoma: updated results of a phase III randomized trial. Int J Radiat Oncol Biol Phys 2006;66:1072-83.

74. Yeoh EK, Holloway RH, Fraser RJ, et al. Anorectal function after three- versus two-dimensional radiation therapy for carcinoma of the prostate. Int J Radiat Oncol Biol Phys 2009;73:46-52.

75. Zietman AL, Bae K, Slater JD, et al. Randomized trial comparing conventional-dose with high-dose conformal radiation therapy in early-stage adenocarcinoma of the prostate: long-term results from proton radiation oncology group/american college of radiology 95-09. J Clin Oncol 2010:28:1106-11.

76. Zietman AL, DeSilvio ML, Slater JD, et al. Comparison of conventional-dose vs high-dose conformal radiation therapy in clinically localized adenocarcinoma of the prostate: a randomized controlled trial. JAMA 2005;294:1233-9.

77. Widmark A. Prospective Randomized Trial Comparing External Beam Radiotherapy versus Watchful Waiting in Early Prostate Cancer (T1b-T2, pN0, Grade 1-2, M0). 2011 annual meeting of the American Society for Therapeutic Radiology and Oncology, ASTRO 2011. http://www.oncolink.org/conferences/article.cfm? $\mathrm{id}=2171 \& \mathrm{ss}=350$

78. Fransson P, Damber JE, Tomic R, et al. Quality of life and symptoms in a randomized trial of radiotherapy versus deferred treatment of localized prostate carcinoma. Cancer 2001;92:3111-19.
79. Fransson P, Damber JE, Widmark A. Health-related quality of life 10 years after external beam radiotherapy or watchful waiting in patients with localized prostate cancer. Scand J Urol Nephrol 2009:43:119-26.

80. Bannuru RR, Dvorak T, Obadan N, et al. Comparative evaluation of radiation treatments for clinically localized prostate cancer: an updated systematic review. Ann Intern Med 2011;155:171-8.

81. Hegarty J, Beirne PV, Walsh E, et al. Radical prostatectomy versus watchful waiting for prostate cancer. Cochrane Database Syst Rev 2010;11:CD006590.

82. Hummel S, Simpson EL, Hemingway $P$, et al. Intensity-modulated radiotherapy for the treatment of prostate cancer: a systematic review and economic evaluation. Health Technol Assess 2010;14:1-108, iii-iv.

83. Koukourakis G, Kelekis N, Armonis V, et al. Brachytherapy for prostate cancer: a systematic review. Adv Urol 2009:327945.

84. Morris DE, Emami B, Mauch PM, et al. Evidence-based review of three-dimensional conformal radiotherapy for localized prostate cancer: an ASTRO outcomes initiative. Int J Radiat Oncol Biol Phys 2005;62:3-19.

85. Olsen DR, Bruland OS, Frykholm G, et al. Proton therapy-a systematic review of clinical effectiveness. Radiother Oncol 2007;83:123-32.

86. Pasquier D, Ballereau C. Adjuvant and salvage radiotherapy after prostatectomy for prostate cancer: a literature review. Int J Radiat Oncol Biol Phys 2008;72:972-9.

87. Peinemann F, Grouven U, Bartel C, et al. Permanent interstitial low-dose-rate brachytherapy for patients with localised prostate cancer: a systematic review of randomised and nonrandomised controlled clinical trials. Eur Urol 2011;60:881-93.

88. Peinemann F, Grouven U, Hemkens LG, et al. Low-dose rate brachytherapy for men with localized prostate cancer. Cochrane Database Syst Rev 2011;7:CD008871.

89. Pieters BR, de Back DZ, Koning CC, et al. Comparison of three radiotherapy modalities on biochemical control and overall survival for the treatment of prostate cancer: a systematic review. Radiother Oncol 2009;93:168-73.

90. Shelley M, Wilt TJ, Coles B, et al. Cryotherapy for localised prostate cancer. Cochrane Database Syst Rev 2007;3:CD005010.

91. Staffurth J. A review of the clinical evidence for intensity-modulated radiotherapy. Clin Oncol (R Coll Radiol) 2010;22:643-57.

92. van Tol-Geerdink JJ, Stalmeier PF, Pasker-de Jong PC, et al. Systematic review of the effect of radiation dose on tumor control and morbidity in the treatment of prostate cancer by 3D-CRT. Int $J$ Radiat Oncol Biol Phys 2006;64:534-43.

93. Viani GA, da Silva LG, Stefano EJ. High-dose conformal radiotherapy reduces prostate cancer-specific mortality: results of a meta-analysis. Int J Radiat Oncol Biol Phys 2012;83:e619-25.

94. Viani GA, Stefano EJ, Afonso SL. Higher-than-conventional radiation doses in localized prostate cancer treatment: a meta-analysis of randomized, controlled trials. Int $J$ Radiat Oncol Biol Phys 2009;74:1405-18.

95. Wilt TJ, MacDonald R, Rutks I, et al. Systematic review: comparative effectiveness and harms of treatments for clinically localized prostate cancer. Ann Intern Med 2008;148:435-48.

96. Resnick MJ, Koyama T, Fan KH, et al. Long-term functional outcomes after treatment for localized prostate cancer. $N$ Engl J Med 2013;368:436-45.

97. Lu G, Ades A. Modeling between-trial variance structure in mixed treatment comparisons. Biostatistics 2009;10:792-805.

98. Sajid S, Kotwal AA, Dale W. Interventions to improve decision making and reduce racial and ethnic disparities in the management of prostate cancer: a systematic review. J Gen Intern Med 2012;27:1068-78.

99. Abdollah F, Schmitges J, Sun M, et al. Comparison of mortality outcomes after radical prostatectomy versus radiotherapy in patients with localized prostate cancer: a population-based analysis. Int J Urol 2012;19:836-44; author reply 844-835.

100. Boorjian SA, Karnes RJ, Viterbo R, et al. Long-term survival after radical prostatectomy versus external-beam radiotherapy for patients with high-risk prostate cancer. Cancer 2011;117:2883-91.

101. Cooperberg MR, Vickers AJ, Broering JM, et al. Comparative risk-adjusted mortality outcomes after primary surgery, radiotherapy, or androgen-deprivation therapy for localized prostate cancer. Cancer 2010;116:5226-34.

102. Sooriakumaran $\mathrm{P}$, Nyberg T, Akre O, et al. Comparative effectiveness of radical prostatectomy and radiotherapy in prostate cancer: observational study of mortality outcomes. BMJ 2014;348:g1502.

103. Zelefsky MJ, Eastham JA, Cronin AM, et al. Metastasis after radical prostatectomy or external beam radiotherapy for patients with clinically localized prostate cancer: a comparison of clinical cohorts adjusted for case mix. J Clin Oncol 2010;28:1508-13. 